Bull. Fac.Agric., Cairo Univ., $66: 1-9$ (2015).

\title{
FARMERS' PERCEPTION OF CLIMATE CHANGE IN RURAL DAMIETTA GOVERNORATE
}

(Received:1.2.2015)

\author{
By \\ A. R. Omar, M. H. Nawar, A. T. El Bendary and H. E. Abou Bakr* \\ Rural Sociology and Agriculture Extension Department \\ *Economic Entomology and Pesticides Department, Faculty of Agriculture, Cairo University
}

\begin{abstract}
Climate change is expected to have severe impacts on various sectors in Egypt. The agricultural sector is the most affected and it is already facing several challenges that hinder its full utilization of its potentials in development. Farmers are thus likely to bear the adverse environmental, economic and social impacts of climate change. Agriculture remains the main source of income for most rural communities in Egypt, and thus adaptation of the agricultural sector is crucial to protect rural livelihoods and to ensure national food security. For successful adaptation, farmers first need to perceive that climate has changed and be aware about the different aspects of climate change. This in return affects the extent to which climate change and its effects are felt by the farmers. The present study examined the degree to which farmers perceive climate variability and its different impacts on agriculture. Farm-level data were collected from 197 farmers in Damietta Governorate using a structured questionnaire. Results showed that the majority of farmers have noticed changes in the climatic patterns particularly in temperature and rainfall. They also noticed changes in crop and livestock productivity and an increase in the rate of pest and disease infection. Farmers' educational level was found to be the main variable that is related to the degree of their perception of climate change.
\end{abstract}

Key words: climate change, farmers, perception,Damietta.

\section{INTRODUCTION}

Climate change has attracted more global concern in the past several decades since the United Nations Conference on Human Environment held in Stockholm in 1972 regarding the impact of human activity on the environment and the various natural resources that should be safeguarded for present and future generations (UN, 1973). Although climate change is a global phenomenon, its impacts would differ spatially. Developing countries in particular are likely to bear more adverse impacts. Egypt is one of the countries that are expected to be heavily affected negatively by climate change as it is predicted to have serious environmental, economic and social impacts on the different sectors (EEAA, 2010). The agricultural sector in Egypt is already facing several challenges, among which water scarcity, population growth and urbanization, and land deterioration (Ministry of Agriculture and Land Reclamation, 2009). Such challenges would be exacerbated under climate change as it is expected to affect water availability and crop productivity. In addition, the most fertile agricultural lands located in the Nile Delta are threatened by the sea-level rise leading to the displacement of people and loss of tens of thousands of jobs. Hence, farmers, -who depend on agriculture as a main source of their living, would be directly impacted by climate change (El Raey, 2010; Abou Hadid, 2008). Accordingly, adaptation is urgently needed in order that such impacts would be reduced or avoided. Yet, for adaptation to be successful, farmers need first to perceive that climate has changed and be aware of current and future risks that they are likely to face. This would help farmers to choose and apply the useful and suitable adaptation methods (Maddison, 2006). Therefore, the present study intended to investigate the level of farmers' perception of the various aspects of climate variability and change and identify the different factors that affect the degree of their perception of climate change. 
The main hypothesis is that, farmers' educational status, their accessibility to information and agricultural inputs and the land tenure type affect farmers' perception of climate change manifestations and effects.

\subsection{Egypt and the Potential impacts of climate change}

Although Egypt has a low contribution in the global Greenhouse Gases' (GHGs) emissions (0.55\% as estimated by UNEP in 2012), it is considered one of the countries that would be severely impacted by climate change taking into account the current problems of high population growth and limited resources in Egypt that impose high pressure on these resources. In Egypt, about $97 \%$ of the population lives on a narrow T-shaped strip of land along the Nile and the deltaic coast representing, only about $4 \%$ of Egypt's total area, where land-use and agriculture, as well as the economic activities are all constrained in this area (Agrawala, et al., 2004 and EEAA, 2010).

Egypt's climate is generally dry and hot in the summer and mild in the winter with rain mainly over the coastal areas where annual precipitation is $200 \mathrm{~mm}$. However, several studies showed that there is a general trend towards warming of the air temperature where a study showed that the mean surface temperature increases by 0.01 to $0.04^{\circ} \mathrm{C}$ per year as recorded in the last decade with projecting future rises with the similar rates per year (Saber, 2007). Likewise, Seyam (2011) found that the annual means of the maximum, minimum and mean temperatures increased by $0.3,0.6$, and $0.4^{\circ} \mathrm{C}$, respectively during the period 1994-2006. Similar data have been recorded by the United Kingdom's Department of Energy and Climate Change (2011) where regionally averaged trends show a stronger warming during summer at $0.3^{\circ}$ $\mathrm{C}$ per decade than during winter at $0.07^{\circ} \mathrm{C}$ per decade.

Regarding precipitation, United Kingdom's Secretary of State for Energy and Climate Change (2011) reported that in the north east there is a decline in the rainfall rate. Correspondingly, Seyam (2011) found that the precipitation rates at the last period (1994-2006) were less than normal over all Egypt, where the mean precipitation during that period was decreasing by $0.43 \mathrm{~mm}$, with the existence of flash floods in autumn over the eastern regions.

Also, several studies showed an increase in the severity and frequency of flash flooding over
Egypt in recent years. An example was the heavy rain that led to the worst flash floods that affected several regions in Egypt including Sinai, the Red Sea coast and Aswan Governorate in January 2010. Such floods resulted in losses estimated by US $\$ 25.3$ million. (United Kingdom's Secretary of State for Energy and Climate Change, 2011). Furthermore, data collected over the period 1961- 2000 showed increases in the number of hot, hazy and misty days, and an increase in the frequency and severity of sand storms and dense haze. Such extreme weather events that Egypt has been suffering from recently have had negative impacts on health, agriculture and livestock and tourism (EEAA, 2010).

\subsubsection{Impact on Coastal areas}

The Egyptian Nile Delta is considered to have economic and strategic importance as it holds the main agricultural lands of Egypt producing almost half of all national crop production and hosts major economic harbors including Alexandria, Rosetta, Damietta, and Port Said. Yet, the Nile Delta region is already suffering a number of problems including high rate of population growth (as it hosts $50 \%$ of the total population), urbanization, excessive erosion rates and local land subsidence, relative low elevation, ecosystem pollution and degradation and lack of appropriate institutional management systems (Ministry of Agriculture and Land Reclamation, 2009). Such problems are expected to be exacerbated due to climate change as Egypt's coastal zones are reported as vulnerable to the various impacts of climate change including sea level rise and the other potential impacts that would affect their water resources, agricultural productivity, tourism, coastal resources and human settlements (EEAA, 2010).

Data obtained during the period 1930-1980 from different coastal locations showed a sea level rise of $11.35 \mathrm{~cm}$ in Rosetta and Damietta. Also, studies were definite about a recession in the shore line in the present time compared to the nineteenth century (Ministry of Agriculture and Land Reclamation, 2009). Moreover, the study of El Raey (2010) stated that the impact of sea level rise would include direct inundation which may happen to low lying Nile delta where Alexandria, Damietta and Port Said may suffer direct inundation and salt water intrusion into the fresh groundwater resources causing soil salinity that would in turn affect agricultural productivity. 


\subsubsection{Impact on water resources:}

Egypt is an arid country and faces water scarcity. Water availability is expected to be further reduced as the population grows and demand increases, falling to $670 \mathrm{~m}^{3}$ per person by 2017 and would reach $350 \mathrm{~m}^{3}$ in 2040 , regardless of the climate change impacts on Egypt's water resources (United Nations Egypt, 2005 and EEAA, 2010).

Egypt's total water budget is estimated at about 58 billion $\mathrm{m}^{3}$, where $95 \%$ of the shares of water resources being from the River Nile, $1.5 \%$ from water aquifers and $3.5 \%$ from rainfall (Alnaggar, 2003). Nevertheless, Egypt is considered more vulnerable to fluctuations in Nile flows than the other nine riparian countries, as these countries are mostly humid and/or less populated than Egypt. In addition, Nile waters are highly sensitive to climate change, both in amount of rainfall and variations in temperature. Since these two factors are also interrelated, the change in temperature, or other factors, would cause changes in precipitation levels thus extremely affecting the Nile flows in the long term (El-Ramady et al., 2013).

Regarding water demand, agriculture consumes about $80 \%$ of the country's water budget. Drinking water and industrial water consume about $10 \%$ each of the country's water budget (EEAA, 2010). Indeed, higher temperatures mean higher rate of evaporation in water bodies and the current loss in Lake Nasser is estimated by ten billion cubic meters. The rise in temperature would mean an increase in the volume of water lost by Egypt's main water reservoir and meanwhile would cause an increase in crops' water demand and consumption (Al Kassas, 2008).

\subsubsection{Impact on Agriculture}

Agriculture represents one of the most important sectors that drive the Egyptian economy, as it contributes approximately by $14.5 \%$ of the GDP and $20 \%$ of all foreign exchange earnings (CIA, 2013; El Nahrawy, 2011). In addition, agriculture has an important role in the social structure of rural areas in Egypt, as agriculture is considered as a family business which encourages family union and stability limiting emigration from rural to urban areas and providing livelihood for about 55\% of the total population (Abou Hadid, 2008).

The agricultural sector in Egypt faces challenges that hinder its development as stated by the Ministry of Agriculture and Land Reclamation (2009). Such challenges include water scarcity, land fragmentation and encroachment, weakness of farmers' organizations, research, extension and veterinary institutions, and finally high rates of losses in the agricultural production. In addition, the high reliance on low efficiency on-farm irrigation systems, and the lack of land leveling decreases irrigation efficiency to $30 \%$ or less which in turn produces more pressure on both agricultural and water sources sectors (EEAA, 2010).

Beside all these problems, the agricultural sector in Egypt is negatively affected by the climate change. As indicated by El Marsafawy (2008), higher temperatures will affect yields and water demand of some major crops in Egypt by the year 2050, where wheat, maize, rice, sunflower seed, sugar-cane, sorghum and soybean yields are expected to decrease and the water demand of these crops is expected to increase. Also, temperature increases evaporation rates which not only increase water demand of crops but also increases soil salinity. Additionally, climate change could affect agriculture through sea level rise as salt water intrusion causes soil salinity and a meter to two meter rise on sea level, as scenarios show, is expected to destroy quarter of the agricultural land in the Delta which would force about 8 million people to emigrate (El Raey, 2010 ; Ministry of Agriculture and Land Reclamation, 2009)

Moreover, climate change is expected to affect available water resources necessitating reducing and rationalizing irrigation water (Eid et al., 2007). Also, a study indicated that climate change would increase the severities of pests and disease which in turns impact crop productivity and quality. Several recent scientific observations conclude that the severity of some pests and diseases affecting major strategic crops has increased in the last decade as a result of temperature increase (EEAA, 2010).

Regarding livestock, its productivity may decrease with higher temperatures, and extreme hot and dry conditions. Additionally, livestock have been more frequently infected by bluetongue disease and Rift Valley fever which become recently widespread and more frequent in Egypt which might be related to climatic factors (Smith et al., 2013).

In conclusion, the Egyptian agriculture is considered to be particularly sensitive to climate change and farmers, who depend mainly on agriculture for living, would be directly and negatively impacted. Thus, it is important to 
question whether the Egyptian agricultural sector is capable of adapting to the current and projected impacts of climate change under the current challenges already facing this sector. Additionally, identifying to what extent such challenges would exacerbate the impacts of climate change on the agricultural sector and water resources.

\subsection{Awareness and Perception of the impacts of climate change as key elements for adaptation}

Adaptation refers to any changes or adjustments in the processes, practices, or structures whether ecological, social or economic aimed at reducing or avoiding potential damages or advantaging from opportunities related to climate change (IPCC, 2001). In this concern, there are two different types of adaptation: a) the autonomous adaptation which is influenced by indigenous knowledge and perception of the different aspects of climate change together with current and future risks, and b) the planned adaptation which is influenced by the presence of appropriate institutions, policies, infrastructure and technology that would aid effective adaptation (Antle, 2009). For instance, Antle, (2009) stated that given sufficient information about changes in climate regimes, well informed farmers are capable of making appropriate changes to adapt agricultural production to changed climate conditions. The rational changes will depend on the ability of decision makers to perceive changes in climate and to take action. In fact, farmers' perceptions of climate change and their capability of adapting are key factors in their response to climate change.

\subsection{Variables of the Study}

To fulfil the objectives of the study, the following variables were selected for measurement.

Farmers' age measured in years.

2.1.1.Farmers' agricultural experience measured by the years of farmers' engagement in agricultural activities which were categorized later on in six categories for non-parametric analysis.

2.1.2.Farmers' educational status was measured using the years that the respondent has successfully completed formal education.

2.1.3.Household educational status was measured by indicating the number of household members being illiterate, who can read and write, with primary, preparatory, secondary and higher education.

2.1.4.Land holding size was measured by the total land holding in feddans

2.1.5.Land tenure of farm whether it is owned or rented or both.

2.1.6.Farmers' perception of climate change manifestation as a dependent variable was measured by ten statements involving the various manifestations of climate change on a three point scale (increased, decreased and no change). Each respondent was given a score based upon his perception where a score of 1 was given to those who perceived the changes and a score of 0 was given to those who did not perceive any changes. Thus, the range of measure extends from 0 to 10 . However, farmers' perception scores were categorized in three groups; less than 5, 5 to less than 7, and 7 and above reflecting low, medium and high perception.

2.1.7.Farmers' perception of climate change effects on agriculture was measured through eight statements involving the various effects of climate change on agriculture through a three point scale (increased, decreased and no change). Then each respondent was given a score based upon the degree to which he perceived a certain negative impact .A score of 3 was given to those who perceived the negative effect, a score of 2 was given to those who did not perceive any changes and a score of 1 was given to those who perceived positive changes all having a theoretical range from 8 to 24 . Then farmers' perception scores were categorized in three categories which are less than 16, from 16 to less than 20, and 20 and above reflecting low, medium and high perception of the negative effects of climate change.

\subsection{Data and Methods}

The study was conducted in Damietta Governorate which is located in the Nile delta along the sides of Damietta branch. Its location made it one of the most vulnerable governorates to sea level rise that is expected to occur due to climate change. Data were collected from two villages, Kafr Saad El Balad village and El Rekabya village. The two villages were chosen based upon the variation in crops cultivated, also, according to the location where a coastal village and an inner village have been chosen to capture the difference, if any, between the two villages. The sample size was calculated based upon the given population of each village using 
the sampling program "Easy Sampling" under the guide of Dr. Abdul Hamid El Abbasy statistics institute, Cairo University. The calculated total sample was 194 farmers. The required representative sample size of the farmers in the two villages accordingly was 106 farmers from Kafr Saad El Balad and 88 from El Rekabia. A list of farmers was provided from the agricultural cooperative in both villages and farmers were chosen using systematic random sampling and data were gathered from 197 farmers in July 2014. Data were collected via individual personal interviews using a pretested structured questionnaire. Descriptive statistics, such as frequencies, in addition to correlation and chi square tests were used for data presentation and analysis.

\section{RESULTS AND DISCUSSION}

\subsection{Farmers' perception of climate change manifestations in the study area}

Table (1) reveals that the majority of respondents $(80.7 \%)$ perceived an increase in temperature over the past 10 years, while only $6.6 \%$ perceived a decrease in temperature and $12.7 \%$ perceived no change in temperature in the past 10 years, and $59.4 \%$ observed an increase in humidity. In addition, $70 \%$ of the farmers observed an increase in the number of hot days over the year and $56.3 \%$ observed a reduction in the duration of the winter season in the past 10

Table (1): Farmers' perception of climate change Manifestations \%.

\begin{tabular}{|l|c|c|c|}
\hline \multicolumn{1}{|c|}{$\begin{array}{c}\text { Climate change } \\
\text { manifestations over } \\
\text { the past 10 years }\end{array}$} & Increased & Decreased & $\begin{array}{c}\text { No } \\
\text { Change }\end{array}$ \\
\cline { 2 - 4 } Temperature change & 80.7 & 6.6 & 12.7 \\
\hline $\begin{array}{l}\text { Number of hot days } \\
\text { over a year }\end{array}$ & 70.1 & 10.6 & 19.3 \\
\hline $\begin{array}{l}\text { Change in rainfall } \\
\text { quantity over a year }\end{array}$ & 7.7 & 82.7 & 9.6 \\
\hline $\begin{array}{l}\text { Number of rainy } \\
\text { days over a year }\end{array}$ & 6.6 & 81.7 & 11.7 \\
\hline $\begin{array}{l}\text { Rainfall intensity in a } \\
\text { time }\end{array}$ & 33.0 & 55.3 & 11.7 \\
\hline $\begin{array}{l}\text { The rate of } \\
\text { occurrence of } \\
\text { unusual dust storms }\end{array}$ & 36.0 & 30.5 & 33.5 \\
\hline $\begin{array}{l}\text { Bouts of frost/ very } \\
\text { cold weather }\end{array}$ & 48.2 & 34.5 & 17.3 \\
\hline Severe heat waves & 84.3 & 6.6 & 9.0 \\
\hline Humidity & 59.4 & 10.7 & 29.9 \\
\hline $\begin{array}{l}\text { Duration of the } \\
\text { winter season }\end{array}$ & 10.2 & 56.3 & 33.5 \\
\hline Soure Collected fien & & & \\
\hline
\end{tabular}

Source: Collected field data years. Besides, $82.7 \%$ of the farmers observed a decline in the amount of rainfall and $81.7 \%$ observed a reduction in the number of rainy days over a year with $55.3 \%$ perceiving a reduction in the intensity of rainfall in the past 10 years.

Regarding extreme weather events, the vast majority $(84.3 \%)$ observed an increase in severe heat waves, $48.2 \%$ perceived an increase in bouts of cold days and only $36 \%$ observed an increase in the rate of unusual dust storms occurrence.

After pooling all measures and classifying the sample according to the level of perception as shown in Table (2), it was concluded that the majority (about 54\%) have high perception of climate change manifestations.

These results are in line with the studies -

Table (2): Farmers' perception of climate change manifestations \%.

\begin{tabular}{|l|c|}
\hline \multicolumn{1}{|c|}{ Degree of perception } & \% \\
\hline Low (less than 5) & 15.7 \\
\hline Medium (from 5 to less than 7) & 30.5 \\
\hline High (7 and above) & 53.8 \\
\hline
\end{tabular}

Source: Collected field data

previously mentioned in the literature- that revealed the changes that occurred in Egypt due to climate change including an observed temperature increase, a decline in rainfall quantity and intensity and an increase in the incidence of extreme weather events. Thus, the results show that farmers have been able to perceive the various changes that occurred due to climate change especially the changes related to temperature and rainfall. By testing the variables that have significant relationship with their perception; the results indicated that the variables can be grouped into the following factors:

\subsubsection{Demographic and social characteristics}

Results from correlation show that there are significant relationships between the degree of farmers' perception to climate change manifestations and educational level of farmers and their household members as shown in Table (3). The results concluded that the higher the educational level of farmers and their family members, the higher the perceptions of the farmers to the different manifestation of climate change. The results, thus, pinpoint that the sensitivity of the farmers to perceive climate change is significantly correlated with education. Since climate change is a natural phenomenon, the farmers were able to perceive it regardless of 
Table (3): Relationship of farmers' perception of climate change manifestations with demographic characteristics of the farmers.

\begin{tabular}{|l|c|}
\hline \multicolumn{1}{|c|}{$\begin{array}{c}\text { Farmers' Demographic } \\
\text { Characteristics }\end{array}$} & $\begin{array}{c}\text { Correlation } \\
\text { coefficients }\end{array}$ \\
\hline Years of formal education & $.223^{* *}$ \\
\hline $\begin{array}{l}\text { Number of illiterate household } \\
\text { members }\end{array}$ & $-.237 * *$ \\
\hline $\begin{array}{l}\text { Number of household members } \\
\text { with primary education }\end{array}$ & $.178^{*}$ \\
\hline $\begin{array}{l}\text { Number of household members } \\
\text { with higher education }\end{array}$ & $.141^{*}$ \\
\hline
\end{tabular}

\section{Source: Analvsis of the field data}

their duration of agricultural experience, income, assets or other economic conditions.

In addition, the results from chi square test showed that there is a significant difference in the degree of perception of the farmers in Kafr Saad El balad and in El Rekabia where the farmers in the latter have been able to perceive and observe climate change manifestations higher than those in Kafr Saad El Balad. This might give a notation that the vulnerability of the location of El Rekabia -being on the coast of Damietta - has made the farmers more sensitive to the changes that occur due to climate change which is in line with the literature. There are differences in the effects of climate change on the two villages especially that the nature of soil in El Rekabia is a sandy soil which makes it more susceptible to extreme weather conditions in particular storms and flash floods. Also this might be a result of the poor agricultural conditions currently prevailing in El Rekabia including absence of extension personnel, poor irrigation water sources (mainly agricultural waste water) which exacerbate the problem of soil salinity, and the nature of the soil being sandy soil.

\subsubsection{Farm unit characteristics and operational status}

The results showed significant relationship with the size of rented farms $\left(.144^{*}\right)$. Hence, farmers who rent farms are more sensitive to the changes resulted from climate change; this might be due to the vulnerability of tenants to shocks in particularly environmental related shocks.

\subsubsection{Accessibility to resources and information}

Testing the distribution of the farmers' perception of climate change manifestations on the various variables using Chi square test, it was found that it is significant with the severity of the problem of accessing pesticides, and the problems related to the presence of pests and diseases and the degree of severity of this problem, the severity of the problem of weeds, and the source of irrigation water as shown in Table (4). This means that the farmers who are strongly affected by problems mainly regarding the presence of pests, diseases and weeds have had made farmers with higher perception about climatic changes. In addition, the farmers accessing poor water quality from agricultural waste water have also higher perception of climate change manifestation.

Moreover, the results from chi square test have shown that the degree of farmers' perception of climate change manifestation has significant relationships with the accessibility of farmers to listen to daily weather forecasting and their accessibility to environmental information regarding getting rid of agricultural waste in a safe manner provided by extension personnel. Thus for farmers who listen to daily weather forecasting have been more able to perceive and recognize that climate had changed. Furthermore, farmers who have access to environmental information have higher perception regarding the manifestations of climate change, this also conclude that extension system,if existed, and having active and effective role- has the ability to provide information and advice the farmers about the different environmental issues in particularly climate change which might in turn shape and guide their attitudes and behavior toward such issues.

\subsection{Farmers' perception of the effects of climate change on agriculture in the study area \\ As shown in Table (5), about half of the} farmers $(50.8 \%)$ observed that crop productivity was negatively affected by the increase in temperature and decline in precipitation. In addition, $75.6 \%$ of the farmers observed that the rate of pest infestation and disease infection has increased in the past ten years. Moreover, they observed that the soil gets dry in a faster rate than before. They also reported that they were not able to cultivate beans and lentils due to the infestation with Broomrape which sharply decreased the productivity of these crops. Also, $77.2 \%$ of the farmers observed an increase in the rate of occurrence of new diseases that were not known before. The results are in line with what was previously mentioned in the literature review regarding the impact of climate change on agriculture. 
Table (4):Relationship of farmers' perception of climate change manifestations with their accessibility to resources and information.

\begin{tabular}{|l|c|}
\hline \multicolumn{1}{|c|}{ Accessibility to Resources and Information } & Chi Square \\
\hline Problems in the agricultural environment (Soil) / Pests and diseases & $\mathbf{. 0 4 3}$ \\
\hline $\begin{array}{l}\text { The degree of severity of the problem regarding agricultural environment (Soil) / Pests and } \\
\text { diseases }\end{array}$ & $\mathbf{. 0 0 5}$ \\
\hline The degree of severity of the problem regarding agricultural environment (Soil) / Weeds & $\mathbf{. 0 0 4}$ \\
\hline Source of irrigation water & $\mathbf{. 0 0 1}$ \\
\hline Listening to the weather forecasting & $\mathbf{. 0 0 7}$ \\
\hline $\begin{array}{l}\text { Kind of services the extension provides: Environmental information regarding getting rid of } \\
\text { agricultural waste in a safe manner }\end{array}$ & $\mathbf{. 0 1 0}$ \\
\hline
\end{tabular}

Source: Analysis of the field data

Table (5):Farmers' perception of climate change effects $\%$.

\begin{tabular}{|l|c|c|c|}
\hline \multirow{2}{*}{\multicolumn{1}{c}{ Observed changes in Agriculture }} & \multicolumn{2}{c|}{$\%$} \\
\cline { 2 - 4 } & Increased & Decreased & No Change \\
\hline Rate of soil dryness & 54.8 & 16.2 & 29.0 \\
\hline Crop productivity due to weather disturbances & 19.3 & 50.8 & 29.9 \\
\hline Rate of pest infestation and disease infection & 75.6 & 15.7 & 8.6 \\
\hline Livestock milk and meat productivity & 18.8 & 63.5 & 15.2 \\
\hline Soil salinity & 31.1 & 40.3 & 28.6 \\
\hline Rate of the occurrence of new diseases & 77.2 & 6.1 & 16.8 \\
\hline Rate of livestock infection with diseases (n=193) & 89.6 & 4.7 & 5.7 \\
\hline Rate of farm animal death (n=193) & 80.9 & 9.8 & 9.3 \\
\hline
\end{tabular}

Source: Collected field data

Regarding livestock production, most farmers $(63.5 \%)$ indicated that livestock productivity of milk and meat has decreased and $89.6 \%$ of the farmers observed that the rate of livestock infection with diseases has increased.

Further data analysis showed that about $75 \%$ of the farmers have medium perception of the various negative effects of climate change and only $15.5 \%$ of them have high perception as shown in Table (6).

Table (6): Farmers' perception of climate change effects\%.

\begin{tabular}{|l|c|}
\hline \multicolumn{1}{|c|}{ Degree of perception } & $\mathbf{\%}$ \\
\hline Low (less than 16) & 9.6 \\
\hline Medium (from 16 to less than 20) & 75.1 \\
\hline High (20 and above) & 15.5 \\
\hline
\end{tabular}

Source: Collected field data

Data obtained also showed that $72.1 \%$ of the farmers have been exposed to several environmental shocks that partially and in several cases completely, destroyed different cultivated crops. These shocks include bouts of cold and snowy weather, sandy storms, flash floods and irregular unexpected rainfall that affected winter and summer crops such as wheat, rice, beans and alfalfa. Therefore, the results show that the farmers had observed changes in the agricultural environment and that they perceived that climate change has negatively affected agriculture both directly and indirectly. By testing the variables that have significant relationship with their perception; the result indicated that the variables can be grouped into the following factors:

\subsubsection{Demographic and social characteristics}

Farmers' perception of the negative impacts of climate change was found to be significantly related with the farmers' educational level $(.042)$, thus, the results give an indication that the farmers' level of education is a key driver in their perception to the negative effects of climate change apart from their economic conditions.

\subsubsection{Accessibility to resources and information}

When testing the distribution of farmers' perception of the negative impacts of climate change on the various variables using Chi square test, it was found that the farmers who moderately and strongly face problem in accessing fuel (.041), and who face problems in fuel prices (.038) and in accessing polluted irrigation water have medium and high perception of the negative effects of climate change on agriculture. 


\section{Summary and Conclusion}

Farmers have been able to perceive that climate has changed and that it has been affecting agriculture both directly and indirectly. The educational level of the farmers and their household members increase their perception of climate change. In addition, the presence of problems regarding the agricultural environment in the studied area and poor accessibility to various resources intensify the problem of climate change and increase the sensitivity and vulnerability of the farmers to the changes that occurred due to climate change. However, the farmers may be relating the negative effects that occurred in the agricultural environment to the inavailability of resources, its poor quality, and lack of extension and veterinary services other than to climate change, especially that their perception of the negative effects of climate change is not high as the results showed above. Also, the farmers accessibility to weather and environmental related information made them better perceive the changes that took place due to climate change.

\section{REFERENCES}

Abou Hadid A. (2008). Climate change and the Egyptian agriculture conundrum. Technical Report of the Association of International Civil Servants (AFICS-Egypt). Egypt, 67-73.

Agrawala S., Moehner A., El Raey M., Conway D., van Aalst M., Hagenstad M. and Smith J. (2004). Development and climate change in Egypt: Focus on coastal resources and the Nile. Organization for Economic Cooperation and Development (OECD). Paris, France. 68 p.

Al Kassas M. (2008). Impact of climate change on agricultural crops and water resource in Egypt. 2008 Technical Report of the Association of International Civil Servants (AFICS-Egypt). Egypt. 23-25.

Alnaggar D.(2003).Water resources management and Policies in Egypt, The Workshop on Policies and Strategies Options for Water Management In Islamic Countries Tehran, Iran, 55-69.

(http://www.bvsde.paho.org/bvsacd/cd29/poli cies.pdf).

Antle M. J. (2009). Agriculture and the food system adaptation to climate change. Resources for the Future. 25 p.

CIA (2013).

https://www.cia.gov/library/publications/theworld-factbook/geos/eg.html
Egyptian Environmental Affairs Agency EEAA (2010). Second National Communication. Arab Republic of Egypt. Cairo. 128 p.

Eid H., El-Marsafawy S. and Ouda S. (2007). Assessing the economic impacts of climate change on agriculture in Egypt. Policy Research Working Paper 4293, The World Bank Development Research Group. 33 p.

El Marsafawy S. (2008). Vulnerability and adaptation of climate change on the agricultural sector in Egypt. 2008 Technical Report of the Association of International Civil Servants (AFICS-Egypt). Egypt. 76- 83.

El Raey Mohamed (2010) . Impact of sea level rise on the Arab Region. University of Alexandria and Regional Center for Disaster Risk Reduction, Arab Academy of Science, Technology and Maritime Transport. $89 \mathrm{p}$.

El-Nahrawy M. (2011). Country Pasture/Forage Resource Profiles EGYPT. Food and Agriculture Organization. Rome, Italy. 44 p.

El-Ramady R. H., El-Marsafawy M. S. and Lewis N.L. (2013). Sustainable Agriculture and Climate Changes in Egypt. E. Lichtfouse (ed.), Sustainable Agriculture Reviews, 12, Springer. $56 \mathrm{p}$.

IPCC (2001). Climate Change 2001: Impacts, Adaptation and Vulnerability. Cambridge University Press, United Kingdom. 881 p.

Maddison D. (2006). The perception of and adaptation to climate change in Africa. CEEPA Discussion Paper No. 10. Center for Environmental Economics and Policy in Africa, University of Pretoria, South Africa. $47 \mathrm{p}$ (ww.ceepa.co.za/uploads/files/CDP10.pdf).

Ministry of Agriculture and Land Reclamation (2009).Sustainable Agricultural Development Strategy 2030(SADS 2030). Cairo, Egypt 31 p.

Saber M. (2007). Environmental consequences of global change in Egypt. Global Change News Letter No. 70: 16-19.

Seyam M. A. (2011). Extreme weather events impacted by climate variability over Egypt. Ph.D. Thesis Department of Astronomy and Space Science and Meteorology, Faculty of Science, Cairo University, Egypt, 128 p.

Smith J., Deck L., McCarl B., Kirshen P., Malley J., Abdrabo M. (2013). Potential impacts of climate change on the Egyptian economy. UNDP. Cairo, Egypt. 49 p.

United Kingdom Department of Energy and Climate Change; Met Office Hadley Center; The University of Nottingham; and Walker 
Institute (2011). Climate: Observations, projections and impacts in Egypt. Met Office, UK. $122 \mathrm{p}$.

United Nations (1973). Report of the United Nations Conference on the Human Environment, Stockholm, 5-16 June 1972.
United Nations publication, Switzerland.77 p. United Nations Egypt (2005). UN Common

Country Assessment: Embracing the Spirit of the Millennium Declaration. Moody Graphic Int.

$$
\begin{aligned}
& \text { دراسه إدراك المزارعيـن بالتغير المناخي وآثاره في ريف محافظة دميـاط } \\
& \text { آية رشدي عمر - محمد حلمي نوار - عزة تهامي البنداري - حسن البنا أبوبكر* } \\
& \text { قسم الاجتماع الريفي و الإرشاد الزراعي و * قسم الحشرات الاقتصادية ـ كلية الزر اعة ـ جامعة القاهرة } \\
& \text { جمهورية مصر العربية }
\end{aligned}
$$

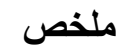

تعد ظاهرة التغير المناخي ظاهرة حقيقية، ومن المتوقع أن تؤثر سلبا على مختلف القطاعلى القيات في في مصر.

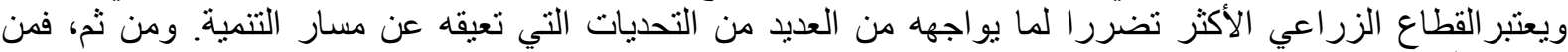

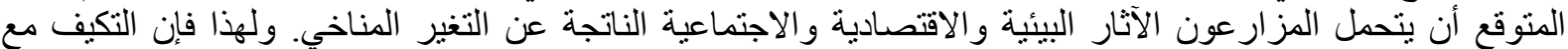

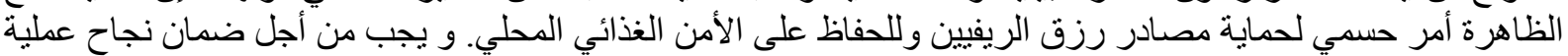

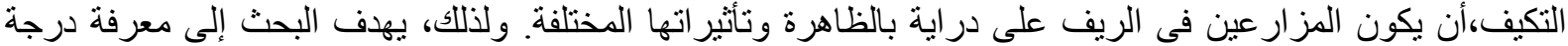

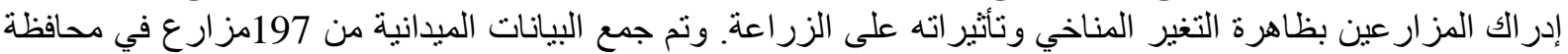

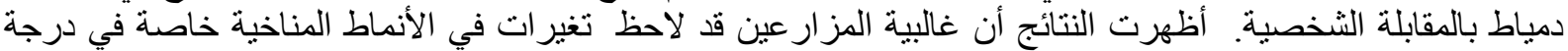

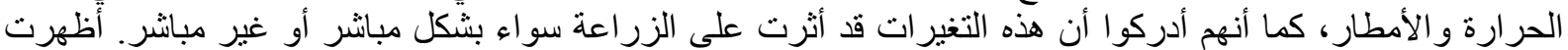

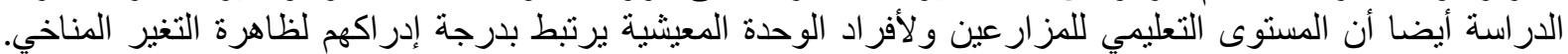

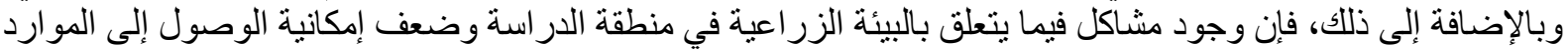

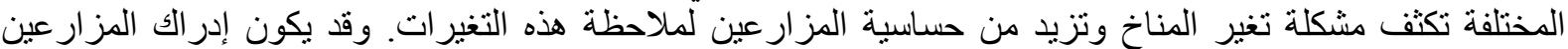

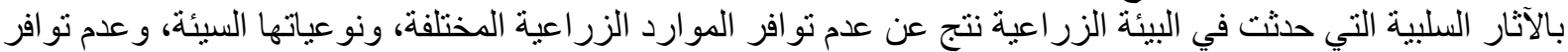

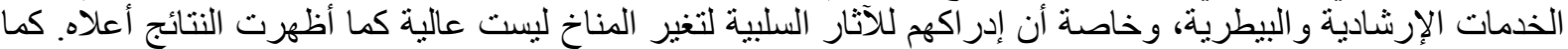

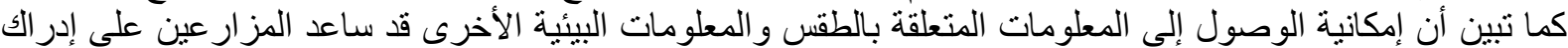

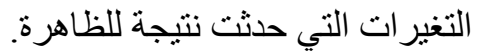

المجلة العلمية لكلية الزراعة - جامعة القاهرة ـ المجلد (66) العدد الأول (ينايرة 2015): 1-9. 